\title{
Multiple Sklerozlu Bireylerde Enerji Koruma Eğitiminin Yorgunluğa ve Aktivite Performansına Etkisi: Olgu serisi
}

Effects of Energy Conservation Education on Fatigue and Occupational Performance in Individuals with Multiple Sclerosis

\section{Sezen TURUNÇ', Gamze EKICi²}

${ }^{1}$ Erg., Hacettepe Üniversitesi, Sağlık Bilimleri Fakültesi, Ergotarapi Bölümü, Ankara

${ }^{2}$ Doç. Dr., Hacettepe Üniversitesi, Sağlık Bilimleri Fakültesi, Ergoterapi Bölümü, Ankara

\section{öz}

Amaç: Çalışmamızın amacı multipl skleroz'lu (MS) bireylerde enerji koruma eğitiminin yorgunluğa ve aktivite performansına etkisini incelemektir. Gereç ve Yöntem: Çalışmamıza 4 MS'li birey dahil edildi. Bireylere 4 hafta, haftada 2 seans olmak üzere toplam 8 seans enerji koruma eğitimi verildi. Değerlendirme ölçekleri olarak yorgunluk için Yorgunluk Şiddet Ölçeği ve Yorgunluk Etki Ölçeği, aktivite performansı ve memnuniyetini ölçmek için ise Kanada Aktivite Performans Ölçümü kullanıldı. 8 seansın sonunda ölçekler tekrar uygulandı ve eğitimin etkinliği incelendi. Sonuçlar: Çalışmamızın sonucunda ilk ve son ölçümler arasında istatistiksel olarak anlamlı bir fark olmamasına rağmen bireylerin yorgunluk puanlarında azalma, aktivite performansında ve memnuniyetinde ise artış görüldü. Tartışma: Yorgunluk MS'li bireylerde bireyin tüm yaşamını etkileyen çok sık karşılaşılan ve tedavi programlarının uygulanmasını olumsuz yönde etkileyebilen önemli bir semptomdur. Bu çalışmanın sonucunda enerji koruma eğitiminin MS'li bireylerin yorgunluk ve aktivite performans ve memnuniyeti üzerine olumlu etkileri olduğu görülmüştür. Bu yüzden MS'li bireylerin tedavi programları planlanırken enerji koruma eğitiminin dahil edilmesi faydalı olacaktır. Daha büyük örneklem içeren grupların dahil edildiği, kontrollü ve uzun dönem takipli çalışmalara intiyaç vardır.

Anahtar Kelimeler: Multipl skleroz; Enerji koruma; Yorgunluk; Aktivite performansı

\section{A B S T R A C T}

Purpose: The aim of this study was to investigate the effects of energy conservation education on fatigue and occupational performance in individuals with multiple sclerosis (MS). Material and Methods: The study included 4 individuals with MS. Energy conservation education was given in a total of 8 sessions, 2 sessions per week for 4 weeks. The Canadian Occupational Performance Measure was used for determining activity performance. Fatigue Impact Scale and Fatigue Severity Scale were used for assessing fatigue. Scales were used again at the end of the 8 sessions and examined the effectiveness of the education. Results: There was no statistically significant difference between the first and last measurement in the results of our study, reduction in fatigue scores, and increase in activity performance and satisfaction. Conclusion: Fatigue is a very common symptom that affects the whole life of an individual in MS and can affect the implementation of treatment programs negatively. Postive effects of energy conservation education on fatigue, occupational performance and satisfaction in individuals with MS was seen in this study. Therefore, it would be useful to include energy conservation education while MS treatment programs are planned. There is a need for controlled and longterm follow-up studies involving larger sample groups

Keywords: Multiple sclerosis; Energy conservation; Fatigue; Occupational performance 
Multiple Skleroz (MS); merkezi sinir sistemindeki inflamasyon ile nöronların etrafını saran miyelin kılıfın kaybı sonucu zamanla akson hasarına neden olan nöroimmün bir hastalıktır (Kumsar, OIgun, Korel,2009). Dünya'da yaklaşık 2,5 milyon MS hastası bulunmaktadır (Matuska, Mathiowetz, Finlayson, 2007). Türkiye'de kesin olmamakla birlikte görülme sıklığı 40/100000 civarındadır (Kumsar ve ark, 2009). MS'in yaygın semptomları; görme problemleri, denge koordinasyonu kaybı, konuşma bozukluğu, tremor, spazm, mesane problemleri, bilişsel bozukluklar ve yorgunluk şeklindedir (Matuska ve ark, 2007). Yorgunluk MS hastalarının \% 80'inde görülmekle birlikte yaklaşık \% 40'ı da yorgunluğu en büyük problem olarak tanımlamıştır (Bowche ve May, 1998; Ayache ve Chalah M, 2017).

MS'te yorgunluk, birey ya da bakım vereni tarafından algılanan ve bireyin alışılagelen aktivitelerini tamamlayamaması ile belirlenen subjektif bir fiziksel ya da mental enerji eksikliğidir (Alğantekin, 2007). MS'te yorgunluk bireylerin fiziksel ve mental fonksiyonlarını, aktivite düzeylerini, istihdam ve toplumsal katılımlarını kısıtlayabilir (Jalón, Lennon, Peoples ve ark, 2012). Yorgunluk MS'li pek çok bireyde kuvvet ve enduransın olumsuz etkilenmesi nedeniyle çeşitli günlük yaşam aktivitelerini yapmakta bireyin zorluk yaşamasına sebep olur. Buna benzer olarak yorgunluk, etkilenen kişinin gerçekleştirmek istediği ölçüde aktivite performansını ve rollerini yerine getirmesinde de zorluk yaşamasına neden olmaktadır (Vanage, Gilbertson, Mathiowetz, 2003).

Aktivite performansı; kültürel olarak tanımlanmış olup, kişinin yaşına ve cinsiyetine uygun, kendisi için anlamlı işi seçebilme, organize edebilme ve bunları yapabilme yeteneği olarak tanımlanabilir (Karayazgan, 2013). MS'te günlük yaşam aktivitelerindeki limitasyonların kişisel bağımsızlık, yaşam kalitesi, bireylerin sosyal rolleri ve ailelerin refahına büyük bir etkisi vardır (Dunn, 2010; Papu ve Stelmasiak, 2012). Bireyin aktivite performans düzeyi ile yaşam kalitesi arasında pozitif yönde iliş̧i olduğu ortaya koyulmuştur (Pekçetin, Bumin, Güngör, Tunç, 2013).

MS'li bireylerde yorgunluğun bireyin günlük yaşam performansına etkisini azaltmak için ergoterapistler de dahil olmak üzere birçok sağlık profesyoneli tarafından çeşitli müdahaleler uygulan- mıştır. Bu müdahaleler kardiyovasküler ve kuvvetlendirme egzersizleri (Dalgas ve ark, 2010), yoga (Cohen, Kietrys, Fogerite ve ark., 2017), bilişseldavranışsal terapi (Twomey, Robinson, 2010; van Kessel ve ark, 2008), enerji koruma eğitimi (Mathiowetz, Finlayson, Matuska ve ark, 2005; Tur, 2016) ve yorgunluk yönetimi eğitimi şeklindedir (Finlayson, Preissner, Cho, 2012). Enerji koruma eğitimi, kronik hastalığı olan kişilerde yorgunluk yönetimi için uygulanan farmakolojik olmayan bir müdahaledir. MS hastaları için ise aktivitelerini nasıl düzenleyeceklerini ve analiz edeceklerini ve yorgunlukla nasıl başa çıkacaklarını öğreten bir eğitimdir (Jalón ve ark, 2012).

Literatürde MS'li bireylerde önemli bir semptom olan yorgunluğun kişinin günlük yaşam aktivitelerini etkilediği görülmüştür (Vanage ve ark, 2003; Özkan Tuncay ve Mollaoğlu, 2017). Buna rağmen bireyin aktivite performansını oluşturan kendine bakım, serbest zaman ve üretkenlik alanlarındaki performansı ve bireylerin bu alanlardaki memnuniyet düzeyleri üzerindeki etkisine yönelik herhangi bir çalışmaya rastlanmamıştır. MS'li bireylerde enerji koruma eğitiminin yorgunluğa ve aktivite performansına etkisi olabileceği hipoteziyle yola çıkılan bu çalışma MS'li bireylerde enerji koruma eğitiminin kişinin genel yorgunluğu ve kendine bakım, üretkenlik ve serbest zaman aktivitelerindeki performans ve memnuniyet düzeyleri üzerine etkisini incelemek amacıyla yapılmıştır.

\section{GEREÇ VE YÖNTEM}

Çalışmamız Aralık - Mayıs 2016 tarihleri arasında Hacettepe Üniversitesi, Sağlık Bilimleri Fakültesi, Ergoterapi Bölümü ve Ankara Multiple Skleroz Derneği'nin işbirliğiyle Ergoterapi Bölümü Eğitim ve Araştırma Ünitelerinde gerçekleştirildi. Çalışmaya MS tanılı 12 birey dahil edildi.

Çalışmaya dahil edilme kriterleri En az 3 aydır MS teşhisi almış olmak, $18-65$ yaş aralığında erişkin olmak, Mini Mental Test'ten 24'ün üzerinde alarak kognitif olarak iletişim kurulabilir olmak, Yorgunluk Şiddet Ölçeği'nden 4'ün üzerinde puan alarak yorgunluk semptomunun bireyde bir en az orta düzeyde olması olarak belirlendi. Dahil edilmeme kriterleri okuma yazma bilmemek, MS yanı sıra özre neden olabilecek farklı hastalıklarının olması, MS'li olup atak döneminde olmak şeklinde belirlenmiştir. 
Çalışmaya katılan herkese çalışma hakkında bilgi verilip, kabul edenlere çalışmanın amaç ve yöntemlerini belirten Helsinki deklerasyonuna uygun bir onam formu imzalatıldı.

Çalışmamız 2 bireyin atak geçirmesi, 4 bireyin gidiş-geliş problemi olması ve 2 bireyin de eğitimi yarıda bırakmasından kaynaklı 4 kişiyle tamamlandı.

Çalışmaya katılan bireyler eğitim öncesi ve 8 seanslık eğitim sonrası olmak üzere iki defa değerlendirildi.

Çalışma kapsamında bireylerin yorgunluk durumları Yorgunluk Şiddet Ölçeği (YŞÖ) ve Yorgunluk Etki Ölçeği (YEÖ) ile aktivite performansı ise Kanada Aktivite Performans Ölçümü (KAPÖ) kullanılarak değerlendirildi.

\section{Değerlendirmeler}

\section{Yorgunluk Şiddet Ölçeği}

Bu ölçekle katıımcıların son bir aydaki yorgunluk durumu değerlendirilmiştir. Dokuz sorudan oluşur. Alınan cevaplar 1-7 arasında puanlanır ve en yüksek puan 63 'tür. Yüksek puan yorgunluğu gösterir. Ölçeğin Türkçe geçerlilik ve güvenilirlik versiyonu Armutlu ve arkadaşları tarafından yapılmıştır (Armutlu, Korkmaz, Keser ve ark, 2007 ).

\section{Yorgunluk Etki Ölçeği}

Katılımcılarda yorgunluğun MS'li bireylerin mental sağlık durumunu ve genel sağlık durumunu nasıl etkilediğini değerlendirmek için kullanılmıştır. Son 1 aydaki yorgunluk durumu değerlendirilmiştir. Ölçek, 10 soru bilişsel durumu, 10 soru fiziksel durumu ve 20 soru psikolojik durumu değerlendirmek üzere toplam 40 sorudan oluşur. Her soru 0 (problem yok) 4 (maksimum problem) puan arasında puanlanmaktadır. En yüksek puan 160 'tır. Yüksek skor yorgunluğu belirtir. Ölçeğin Türkçe geçerlilik ve güvenilirlik versiyonu Armutlu ve arkadaşları tarafından yapılmıştır (Armutlu, Korkmaz, Keser ve ark, 2007).

\section{Kanada Aktivite Performans Ölçümü}

Çalışmamızda MS'li bireylerin aktivite performansı ve memnuniyet düzeyini değerlendirmek amacıyla kullanılmıştır. Öncelikle bireylerden kendine bakım, iş ve üretkenlik, serbest zaman aktiviteleri alanlarında yaşadıkları problemlerini belirlemesi istenir. Daha sonra belirledikleri her aktiviteye likert skalasına göre $0-10$ arasında bir önem değeri vermesi istenir (0-Hiç önemli değil, 10-çok önemli). Sonraki aşamada kendileri için en önemli en az 1, en fazla 5 aktiviteyi seçmeleri ve bu aktivitelerin her biri için yine likert skalasına göre 0-10 arasında performans ve memnuniyet puanı vermeleri istenir. Elde edilen performans ve memnuniyet puanları toplanarak bireyin belirttiği aktivite sayısına bölünür ve toplam performans ve memnuniyet puanları elde edilir (Law, Bapiste, Carswel ve ark, 2005).

\section{Müdahale Programı}

Katılımcılara haftada 2 kez 4 hafta olmak üzere toplam 8 seans enerji koruma eğitimi verildi. Eğitim öncesinde ve 8 seans sonrasında yorgunluk ve aktivite performansı değerlendirildi.

Enerji koruma eğitimi; yorgunluğa neden olan kronik hastalıklara sahip olan bireyler için Packer ve arkadaşları tarafından geliştirilmiştir (Packer, Brink, Sauriol, 1995). Bu eğitim; dinlenmenin önemi, enerjiyi depolama ve kullanma, vücut mekaniğinin uygun kullanımı, aktivitelerin organize edilmesi, yardımcı teknoloji kullanımı, öncelikleri ve standartları ayarlama, günlük yaşamdaki dengeyi sağlama gibi stratejileri içerir. Bireyin günlük yaşamdaki aktivitelerini yerine getirirken mevcut enerjisini optimum seviyede kullanmasını sağlamayı amaçlar.

Bireylere verilen eğitimin içeriği;

1. hafta zaman yönetimi, öncelikleri ve standartları belirleme

2. hafta vücut mekaniği, postür, ergonomik prensipler

3. hafta kendine bakım, üretkenlik ve serbest zaman aktiviteler arasındaki denge

4. hafta yardımcı araçların tanıtımı şeklindedir.

\section{İstatistiksel Analiz}

İstatistiksel analizlerde 'SPSS 16 for Windows' istatistik programı kullanılmıştır. Bireylerin sosyodemografik özellikleri, cinsiyet, eğitim, medeni durum, yaşadığı ortam, çocuk sahibi olma, sosyal güvence, yardımcı alet kullanımı, yaş ve vücut kütle indeksi gibi tanımlayıcı verilerde uygunluğuna göre frekans ve/veya ortalama \pm Standart Sapma $(\mathrm{X} \pm \mathrm{SS})$ değerleri verilmiştir. Yorgunluk, aktivite performansı ve memnuniyeti için tedavi önce- 
si ve 8 seans sonra elde edilen veriler 'Wilcoxon Eşleştirilmiş Test' kullanılarak değerlendirilmiştir. İstatistiksel anlamlılık düzeyi $p<0.05$ olarak kabul edilmiştir.

Tablo 1. Sosyodemografik bilgiler

\begin{tabular}{|c|c|c|}
\hline \multirow{2}{*}{ Cinsiyet } & & n (\%) \\
\hline \multirow{2}{*}{ Eğitim } & Kadın & (75) \\
\cline { 2 - 3 } & Erkek & 2 (50) \\
\hline \multirow{2}{*}{ Medeni Durum } & ilköğretim & 2(50) \\
\cline { 2 - 3 } & Lise & 1(25) \\
\hline Yaşadığı Ortam & Bekar & 3(75) \\
\hline Çocuk sahibi olma & Evli & $4(100)$ \\
\hline Sosyal Güvence & Ailesi ile birlikte & $4(100)$ \\
\hline \multirow{2}{*}{ Yardımcı Alet (Araç) } & Var & $1(25)$ \\
\cline { 2 - 3 } & Var & $3(75)$ \\
\hline
\end{tabular}

VKI: Vücut Kütle İndeksi

Tablo 2. Eğitim öncesi ve sonrası yorgunluk ölçekleri sonuçları

\begin{tabular}{|c|c|c|c|c|c|}
\hline & & $\begin{array}{l}\text { Enerji Koruma } \\
\text { Eğitimi Öncesi }\end{array}$ & $\begin{array}{l}\text { Enerji Koruma } \\
\text { Eğitimi Sonrası }\end{array}$ & & \\
\hline & & $x \pm \mathrm{SS}$ & $x \pm S S$ & z & p \\
\hline \multicolumn{2}{|c|}{ Yorgunluk Şiddet Ölçeği } & $60 \pm 1,414$ & $54,75 \pm 1,25$ & $-1,826$ & 0,06 \\
\hline \multirow{4}{*}{$\begin{array}{l}\text { Yorgunluk } \\
\text { Etki Ölçeği }\end{array}$} & $\begin{array}{l}\text { Kognitif } \\
\text { Yorgunluk }\end{array}$ & $23,25 \pm 1,25$ & $19,75 \pm 2,36$ & $-1,857$ & 0,06 \\
\hline & $\begin{array}{l}\text { Fiziksel } \\
\text { Yorgunluk }\end{array}$ & $25,75 \pm 2,21$ & $23,75 \pm 4,34$ & $-1,604$ & 0,10 \\
\hline & $\begin{array}{l}\text { Psikolojik } \\
\text { Yorgunluk }\end{array}$ & $41,5 \pm 2,64$ & $37,75 \pm 2,87$ & $-1,841$ & 0,06 \\
\hline & Toplam & $90,5 \pm 5,25$ & $81,25 \pm 6,80$ & $-1,826$ & 0,06 \\
\hline
\end{tabular}

\section{SONUÇLAR}

Puan incelemesi yapıldığında verilen eğitim sonrasında bireylerin yorgunluk seviyelerinde puansal azalma olduğu görülmüştür.

Yapılan değerlendirmeler sonucunda bireylerin aktivite performans ve memnuniyet puanlarında artış meydana gelmiştir. 
Tablo 3. Eğitim öncesi ve sonrası aktivite performans ve memnuniyet puanları

\begin{tabular}{|c|c|c|c|c|c|c|}
\hline & & & \multicolumn{2}{|c|}{$\begin{array}{l}\text { Enerji Koruma } \\
\text { Eğitimi Öncesi }\end{array}$} & \multicolumn{2}{|c|}{$\begin{array}{l}\text { Enerji Koruma } \\
\text { Eğitimi Sonrası }\end{array}$} \\
\hline & & & $\begin{array}{l}\text { Performans } \\
\text { Puanı }\end{array}$ & $\begin{array}{l}\text { Memnuniyet } \\
\text { Puanı }\end{array}$ & $\begin{array}{l}\text { Performans } \\
\text { Puanı }\end{array}$ & $\begin{array}{c}\text { Memnuniyet } \\
\text { Puanı }\end{array}$ \\
\hline \multirow{12}{*}{$\begin{array}{l}\text { Kendine } \\
\text { Bakım }\end{array}$} & \multirow{4}{*}{ Kişisel Hijyen } & Vaka 1 & - & - & - & - \\
\hline & & Vaka 2 & - & - & - & - \\
\hline & & Vaka 3 & 3 & 3 & 5 & 5 \\
\hline & & Vaka 4 & - & - & - & - \\
\hline & \multirow{4}{*}{$\begin{array}{c}\text { Fonksiyonel } \\
\text { Mobilite }\end{array}$} & Vaka 1 & 4 & 4 & 6 & 6 \\
\hline & & Vaka 2 & 2 & 3 & 5 & 5 \\
\hline & & Vaka 3 & 5 & 3 & 5 & 5 \\
\hline & & Vaka 4 & 7 & 6 & 8 & 8 \\
\hline & \multirow{4}{*}{$\begin{array}{c}\text { Toplumsal } \\
\text { Başarı }\end{array}$} & Vaka 1 & 3 & 1 & 5 & 6 \\
\hline & & Vaka 2 & - & - & - & - \\
\hline & & Vaka 3 & - & - & - & - \\
\hline & & Vaka 4 & - & - & - & - \\
\hline \multirow{12}{*}{ Üretkenlik } & \multirow{4}{*}{$\begin{array}{c}\text { Maaşlı/maaşsız } \\
\text { İş }\end{array}$} & Vaka 1 & - & - & - & - \\
\hline & & Vaka 2 & - & - & - & - \\
\hline & & Vaka 3 & - & - & - & - \\
\hline & & Vaka 4 & - & - & - & - \\
\hline & \multirow{4}{*}{ Ev İşi Yönetimi } & Vaka 1 & - & - & - & - \\
\hline & & Vaka 2 & - & - & - & - \\
\hline & & Vaka 3 & - & - & - & - \\
\hline & & Vaka 4 & 6 & 3 & 6 & 6 \\
\hline & \multirow{3}{*}{ Oyun/Okul } & Vaka 1 & - & - & - & - \\
\hline & & Vaka 2 & - & - & - & - \\
\hline & & Vaka 3 & - & - & - & - \\
\hline & & Vaka 4 & - & - & - & - \\
\hline \multirow{12}{*}{$\begin{array}{l}\text { Serbest } \\
\text { Zaman }\end{array}$} & \multirow{4}{*}{$\begin{array}{c}\text { Sessiz } \\
\text { Rekreasyon }\end{array}$} & Vaka 1 & - & - & - & - \\
\hline & & Vaka 2 & - & - & - & - \\
\hline & & Vaka 3 & 3 & 0 & 3 & 3 \\
\hline & & Vaka 4 & - & - & - & - \\
\hline & \multirow{4}{*}{$\begin{array}{c}\text { Aktif } \\
\text { Rekreasyon }\end{array}$} & Vaka 1 & - & - & - & - \\
\hline & & Vaka 2 & - & - & - & - \\
\hline & & Vaka 3 & - & - & - & - \\
\hline & & Vaka 4 & - & - & - & - \\
\hline & \multirow{4}{*}{ Sosyalizasyon } & Vaka 1 & - & - & - & - \\
\hline & & Vaka 2 & - & - & - & - \\
\hline & & Vaka 3 & - & - & - & - \\
\hline & & Vaka 4 & - & - & - & - \\
\hline
\end{tabular}




\section{TARTIŞMA}

Multiple sklerozlu bireylerde enerji koruma eğitimin yorgunluğa ve aktivite performansına olan etkisinin incelenmesi amacıyla yapılan çalışmada bireylerin yorgunluk düzeylerinde azalma, aktivite performansında ve memnuniyetinde artış görüldü.

Sauter ve arkadaşları 32 MS'li bireye verdiği 6 haftalık enerji koruma eğitiminin sonucunda yorgunluk şiddetinde ve psikolojik yorgunlukta anlamlı bir gelişme olmamasına rağmen bilişsel, fiziksel ve genel yorgunluk düzeylerinde anlamlı bir gelişme olduğunu ifade etmişlerdir (Sauter, Zebenholzer, Hisakawa ve ark, 2007). Çalışmamızda ise eğitim sonrasında bilişsel, fiziksel, psikolojik yorgunluk ve genel yorgunluk puanlarında azalma, aktivite performans ve memnuniyet sonuçlarında artma görüldü.

MS'e özgü bulgular nedeniyle özellikle atakların olduğu dönemlerde bireyin günlük yaşam aktivitelerindeki kısıtıııklar kişisel bağımsızlık, yaşam kalitesi, kişilerin sağlık ve iyilik halleri halleri oldukça olumsuz yönde etkilenmektedir (Dunn, 2010; Papu ve Stelmasiak, 2012). MS'li bireylere yorgunluk yönetimine yönelik yapılan çalışmada 3 haftalık ergoterapi programı sonucunda bireylerin yorgunluk seviyelerinde düşüş, üretkenliklerinde artış olduğu ortaya koyulmuştur (Bowcher, May, 1998). Vanage ve arkadaşları yaptığı çalışmada ilerleyici MS tanılı bireylere 8 haftalık enerji koruma eğitimi vermiş. Bunun sonucunda kognitif, fiziksel ve psikolojik yorgunluk azalarak bireylerdeki yorgunluk olumlu etkilenmiş (Vanage ve ark, 2003). Zaman yönetimi, öncelikleri ve standartları belirleme, vücut mekaniği, postür, ergonomik prensipler, kendine bakım, üretkenlik ve serbest zaman aktiviteler arasındaki denge ve yardımcı araçların tanıtımını içeren müdahalemiz sonucunda eğitimin yorgunluğa, aktivite performansına ve memnuniyetine olumlu etkide bulunduğu görüldü. Fiziksel aktivitenin de yaşam kalitesine olumlu etkisi olduğu gösterilmiştir (Kurt EE, ve ark, 2017)

Yorgunluk ve aktivite performans ve memnuniyeti üzerine olumlu etkileri puansal olarak görülen enerji koruma eğitiminin istatistiksel olarak anlamlı bir sonuç vermemesini örneklem sayımızın çok düşük olmasının sebep olabileceğini düşünmekteyiz. Ayrıca MS'in doğası gereği zaman zaman atakların olması bireylerin rehabilitasyon merkezine gidiş gelişleri gibi kısıtlılıklar da örneklem başlangıç sayısının oldukça düşmesine neden olmuştur.

Sonuç olarak, MS'li bireylerde enerji koruma eğitiminin kişinin genel yorgunluğu ve kendine bakım, üretkenlik ve serbest zaman aktivitelerindeki performans ve memnuniyetine olumlu etkilerinin bireysel istek ve algının ortaya koyularak gösterilmesi açısından önemlidir. Bu çalışmada yorgunluk ve bireyin aktivite performans alanları beraber incelenmiştir. Özellikle kişiye özel ve bireyin kendi istekleri ve algısına dayandırılarak yapılan incelemelerde alınan olumlu sonuçlar ile MS'li bireylerin rehabilitasyon programı planlanırken enerji koruma eğitiminin programa dahil edilmesi gereği ortaya daha güçlü şekilde koyulmuştur. Olumlu sonuçlara rağmen, daha geniş örneklem gruplarının dahil edildiği kontrollü ve uzun dönem takipli ileri çalışmalara intiyaç duyulmaktadır.

\section{KAYNAKÇA}

Alğantekin, H. (2013). Multiple sklerozlu hastalarda yorgunluğun denge üzerine etkisi. İstanbul Bilim Üniversitesi, Sağlık Bilimleri Enstitüsü, Fizyoterapi Ve Rehabilitasyon Yüksek Lisans Tezi, İstanbul.

Armutlu, K., Keser, I., Korkmaz, N., Akbiyik, D.I., Sümbüloğlu, V., Güney, Z., \& ark. (2007). Psychometric study of Turkish version of Fatigue Impact Scale in multiple sclerosis patients. J Neurol Sci, 15, 255(1-2), 64-8.

Armutlu, K., Cetisli, K. N., Keser, I., Sumbuloglu, V., Irem, A., Derya, G. Z., ve ark. (2007). The validity and reliability of the Fatigue Severity Scale in Turkish multiple sclerosis patients, Int J Rehabil Res, 30(1),81-5.

Ayache, S.S., \& Chalah, M.A. (2017). Fatigue in multiple sclerosis - Insights into evaluation and management. Neurophysiol Clin. pii: S0987-7053(16)30384-7. doi:10.1016/j.neucli.2017.02.004.

Bowcher, H. , \& May, M. (1998). Occupational therapy for the management of fatigue in multiple sclerosis. $\mathrm{Br} \mathrm{J}$ Occup Ther, 61(11),488-92.

Cohen, E.T., Kietrys, D., Fogerite, S.G., Silva, M., Logan, K., Barone, D.A. \& et.al (2017). Feasibility and impact of an 8-week integrative yoga program in people with moderate multiple sclerosis-related disability: A pilot study. Int J MS Care, 19(1), 30-39. doi: 10.7224/1537-2073.2015-046.

Dalgas, U., Stenager, E., Jakobsen, J., Petersen, T., Hansen, H. J., \& Knudsen, C. (2010). Fatigue, mood and quality 
of life improve in MS patients after progressive resistance training. Multiple Sclerosis, 16, 480-490.

Dunn, J. (2010). Impact of mobility impairment on the burden of caregiving in individuals with multiple sclerosis. Expert Rev Pharmacoecon Outcomes Res, 10(4),433-40. doi: 10.1586/erp.10.34.

Finlayson, M., Preissner, K., \& Cho, C. (2012). Outcome moderators of a fatigue management program for people with Multiple Sclerosis. Am J Occup Ther, 66(2),187-97.

Karakoç Kumsar, A., Olgun, N., \& Korel, Ö. (2009). Multiple Sklerozlu hastada yorgunluğun değerlendirilmesi. Maltepe Üniversitesi Hemşirelik Bilim ve Sanatı Dergisi, 2(2),100-103.

Karayazgan S. (2013). Şizofreni hastalarına bakımverenlerin aktivite, aktivite performansı ve sağlıkla ilgili yaşam kalitelerinin incelenmesi. Hacettepe Üniversitesi Sağlık Bilimleri Enstitüsü, Ergoterapi Yükseklisans tezi, Ankara.

Kurt, E. E., Büyükturan, B., Büyükturan, Ö., Erdem, H.R. \& Tuncay, F.(2017). Effects of Ai Chi on balance, quality of life, functional mobility, and motor impairment in patients with Parkinson's disease. Disabil Rehabil. doi.org/10.1080/09638288.2016.1276972

Law, M., Bapiste, S., Carswe,l A., \& McColl, M.A. (2005). Canadian Occupational Performance Measure. CAOT Publications ACE. Can J Occup Ther, 71(4),210-22.

Mathiowetz, V., Finlayson, M., Matuska, K., Chen, H. Y., \& Luo, P. (2005). A randomized trial of energy conservation for persons with multiple sclerosis. Multiple Sclerosis, 11, 592-601.

Mathiowetz, V., Matuska, K., \& Murphy, M. (2001). Efficacy of an energy conservation course for persons with multiple sclerosis. Arch Phys Med Rehabil, 82(4), 449-56.

Matuska, K., Mathiowetz, V., \& Finlayson, M. (2007). Use and perceived effectiveness of energy conservation strategies for managing multiple sclerosis fatigue. $\mathrm{Am}$ J Occup Ther,61(1), 62-9.

Özkan, T.F., \& Mollaoğlu, M. (2017). Effect of the cooling suit method applied to individuals with multiple sclerosis on fatigue and activities of daily living. J Clin Nurs. doi: 10.1111/jocn.13788.

Packer, T. L., Brink, N., \& Sauriol, A. (1995). Managing fatigue: A six-week course for energy conservation. Tucson: Therapy Skill Builders.

Papuć, E., \& Stelmasiak, Z. (2012). Factors predicting quality of life in a group of Polish subjects with multiple sclerosis: accounting for functional state, socio-demographic and clinical factors. Clin Neurol Neurosurg, 114(4), 341-6. doi: 10.1016/j. clineuro.2011.11.012

Pekçetin, S., Bumin, G., Güngör, T., \& Tunç, S. (2013). Kemoterapi alan jinekolojik kanserli hastalarda algılanan aktivite performansının toplumsal katılım ve yaşam kalitesi üzerine olan etkisi. Ergoterapi ve Rehabilitasyon Dergisi, 1(2), 31-40.

Sauter, C., Zebenholzer, K., Hisakawa, J., Zeitlhofer, J., \& Vass, K. (2007). A longitudinal study on effects of a six-week course for energy conservation for multiple sclerosis. Mult Scler, 14(4), 500-5.

Tur C. (2016). Fatigue management in multiple sclerosis. Curr Treat Options Neurol, 18(6),26. doi: 10.1007/ s11940-016-0411-8. Review.

Twomey, F., \& Robinson, K. (2010). Pilot study of participating in a fatigue management programme for clients with multiple sclerosis. Disabil Rehabil, 32, 791-800.

Vanage, S., Gilbertson, K., \& Mathiowetz, V. (2003). Effects of an energy conservation course on fatigue impact for persons with progressive multiple sclerosis. Am J Occup Ther, 57(3),315-23.

Van Kessel, K., Moss-Morris, R., Willoughby, E., Chalder, T., Johnson, M.H., \& Robinson, E. (2008). A randomized controlled trial of cognitive behavior therapy for multiple sclerosis fatigue. Psychosomatic Medicine, 70, 205-213. 
